\title{
Abdominal palpation had moderate sensitivity and specificity for detecting abdominal aortic aneurysm
}

Fink HA, Lederle FA, Roth CS, et al. The accuracy of physical examination to detect abdominal aortic aneurysm. Arch Intern Med 2000 Mar 27;160:833-6.

\section{QUESTION: In adults who were $>50$ years of age, is abdominal palpation accurate for detecting abdominal aortic aneurysm (AAA)?}

Design

Blinded comparison of abdominal palpation with ultrasonography.

\section{Setting}

Veterans Affairs Medical Center, Minneapolis, Minnesota, USA.

\section{Participants}

200 participants who were 51 to 88 years of age (mean age $73 \mathrm{y}, 98 \% \mathrm{men})$ and had known AAAs $(\geqslant 3 \mathrm{~cm}$ in diameter $)(n=99)$ or known absence of AAAs $(n=101)$.

Description of test and diagnostic standard 2 internists independently examined patients who were in a supine position with raised knees and relaxed abdomen (400 examination findings). Internists attempted to identify aortic pulsation by deep palpation of the upper abdomen. An AAA was considered to be present when the aorta was judged to be $\geqslant 3 \mathrm{~cm}$ in maximum diameter after accounting for skinfold thickness. The diagnostic standard was ultrasonography.

\section{Main outcome measures}

Sensitivity and specificity for detecting AAA.
Source of funding: not stated.

For correspondence:

Dr F A Lederle,

Department of

Medicine (III-O),

Minneapolis Veterans

Affairs Medical Center,

1 Veterans Drive,

Minneapolis, $M N$

55417, USA. Fax +1

6127252118.

\section{Main results}

The table shows the results. Palpation had higher sensitivity in patients with abdominal girth $<100 \mathrm{~cm}(40$ inches) than in those with girth $\geqslant 100 \mathrm{~cm}(\mathrm{p}<0.001)$, in patients whose abdomens were not rated as obese than in those whose abdomens were rated as obese $(\mathrm{p}<0.001)$, and in patients whose abdomens were not rated as tight than in those whose abdomens were rated as tight $(\mathrm{p}<0.005)$ (table). Sensitivity was high in patients whose aortas were palpable, including those whose abdomens measured $\geqslant 100 \mathrm{~cm}$ (table).
Test characteristics of abdominal palpation for detecting abdominal aortic aneurysm*

\begin{tabular}{lllll}
\hline Patient group & Sensitivity $(95 \% \mathrm{Cl})$ & Specificity (Cl) & +LR & - LR \\
\hline All examinations & $68 \%(60$ to 76$)$ & $75 \%(68$ to 82$)$ & 2.7 & 0.43 \\
\hline Girth $<100 \mathrm{~cm}$ & $91 \%$ & $64 \%$ & 2.5 & 0.14 \\
\hline Girth $\geqslant 100 \mathrm{~cm}$ & $53 \%$ & $83 \%$ & 3.2 & 0.56 \\
\hline Abdomen not obese & $89 \%$ & $66 \%$ & 2.6 & 0.17 \\
\hline Abdomen obese & $46 \%$ & $84 \%$ & 2.9 & 0.64 \\
\hline Abdomen not tight & $74 \%$ & $68 \%$ & 2.3 & 0.38 \\
\hline Abdomen tight & $52 \%$ & $89 \%$ & 4.7 & 0.54 \\
\hline Aorta palpable & $88 \%$ & $56 \%$ & 2.0 & 0.22 \\
\hline Girth $\geqslant 100 \mathrm{~cm}$ and aorta palpable & $82 \%$ & $59 \%$ & 2.0 & 0.30 \\
\hline
\end{tabular}

*LRs defined in glossary.

\section{Conclusions}

In adults who were $>50$ years of age, abdominal palpation had moderate sensitivity and specificity for detecting abdominal aortic aneurysm. Sensitivity was higher in patients whose abdomens were $<100 \mathrm{~cm}$ (40 inches) and were rated as not being tight or obese. Sensitivity was high for patients with palpable aortas.

\section{COMMENTARY}

AAA may remain asymptomatic until rupture, which makes the diagnosis of the condition too important to be missed. The study by Fink $e t a l$ shows that abdominal palpation may not be accurate enough to detect AAA or to assess changes in size. In marked contrast to elective procedures, the mortality of surgical repair for rupture remains high. A multicentre randomised study on ultrasonographic screening of AAAs is currently being done in the UK. However, a previous study showed a benefit for screening, with $55 \%$ fewer ruptures in men who were screened than in men who were not; this study also showed that the incidence of rupture in women was low. ${ }^{1}$ First degree relatives of patients with AAAs should also be screened. ${ }^{2}$ The potential rupture rate (actual rupture rate plus elective surgery rate) for aneurysms measuring 3.0 to $4.4 \mathrm{~cm}$ in diameter is $2.1 \%$ /year. ${ }^{3}$ This rate increases to $10.2 \%$ /year for aneurysms measuring 4.5 to 5.9 $\mathrm{cm}$. Surgery is recommended for aneurysms $>6 \mathrm{~cm}$ and for those with diameters between 4.5 and $5.9 \mathrm{~cm}$ if they increase by $>1 \mathrm{~cm} /$ year or if they become symptomatic.

Until evidence from randomised controlled trials is available, I recommend that all men should have an ultrasonogram at 65 years of age. Any patients with an aortic aneurysm diameter of 3 to $4 \mathrm{~cm}$ should have an annual ultrasonogram. Patients with aneurysms that have a diameter of 4 to $5 \mathrm{~cm}$ should have scans twice/year and those with a diameter of 5 to $5.5 \mathrm{~cm}$ should have scans 4 times/year. An aneurysm that increases by $1 \mathrm{~cm}$ in 1 year should be treated, as should an aneurysm that becomes tender.

Peter R Taylor, MA, MChir Guy's Hospital London, $U K$

1 Scott RA, Wilson NM, Ashton HA, et al. Influence of screening on the incidence of ruptured abdominal aortic aneurysm: 5-year results of a randomized controlled study. Br I Surg 1995;82:1066-70.

2 Baird PA, Sadovnick AD, Yee IM, et al. Sibling risks of abdominal aortic aneurysm. Lancet 1995;346:601-4.

3 Scott RA, Tisi PV, Ashton HA, et al. Abdominal aortic aneurysm rupture rates: a 7-year follow-up of the entire abdominal aortic aneurysm population detected by screening. I Vasc Surg 1998;28:124-8. 